East African Medical Journal Vol. 81 No. 4 April 2004

PROFILE OF SUICIDE IN DAR ES SALAAM

N. K. Ndosi, MD, PhD, Associate Professor, Department of Psychiatry, M. P. Mbonde, MD, MMed, PhD, Senior Lecturer, Department of Morbid Anatomy and Pathology, and E. Lyamuya, MD, PhD, Associate Professor, Department of Immunology and Microbiology, Muhimbili University College of Health Sciences, P.O Box 65051, Dar es Saalam, Tanzania

Request for reprints to: Dr. N. K. Ndosi, Department of Psychiatry, Muhimbili University College of Health Sciences, P.O. Box 65051, Dar-es-Saalam, Tanzania

\title{
PROFILE OF SUICIDE IN DAR ES SALAAM
}

\author{
N. K. NDOSI, M. P. MBONDE and E. LYAMUYA
}

\begin{abstract}
Objective: To investigate individual socio-demographic characteristics of suicides, the reasons, methods and means employed to commit suicide.

Design: A descriptive prospective study of suicides. A structured questionnaire was employed to enquire the details of the itemised objectives.

Setting: Muhimbili National Hospital - in urban Dar es Salaam.

Subjects: Fifty three males and 47 females consecutive suicides aged 15 to 59 years

Results: The mean age for suicides was found to be $\mathbf{2 8 . 2}$ years. Males were more than females and were ten years older. Sixty two percent of the subjects were single, $30 \%$ married. Seventy two percent had primary school education, $19 \%$ secondary education. Main reasons for committing suicide were established in 61 cases of which $57.3 \%(35 / 61)$ were due to severe marital and family conflicts, overwhelming disappointments in love affairs and unwanted pregnancies. Eleven subjects with chronic somatic illnesses killed themselves due to unbearable physical pain and overwhelming economic deprivations motivated ten subjects to take their lives. Sixty nine subjects poisoned themselves predominantly using anti-malarials and pesticides while 27 hanged themselves. A third of the suicides consumed alcohol frequently and a quarter of the suicides were HIV positive, a rate twice the national prevalence for sexually active adults.

Conclusion: Comparatively, women became vulnerable to suicide at a younger age. Dysfunctional social networks played a predominant role among suicides. Family and marital conflicts need closer social attention and timely counseling. Patients with chronic medical conditions and frequent alcohol use need effective exploration concerning suicidal ideation to avert self-annihilation. A policy to control prescriptions of toxic drugs including pesticides is overdue.
\end{abstract}

\section{INTRODUCTION}

Suicide is the direct act of killing oneself on one's own authority. It is among top ten causes of death in most countries that report rates and it is also one of the top two or three causes of death among the young(1). For each unsuccessful suicide, there are eight other estimated attempts. Among people over 75 years of age, the annual rate is three times the average and males may account for $90 \%$ of suicides. In the age between 15 and 25 years, suicide is however rising and it is now the third leading cause of death. Although females are more likely to attempt suicide, males are more likely to succeed(2). In at least $90 \%$ of suicides, there is an associated mental or emotional disorder such as depression, alcoholism, drug abuse and schizophrenia. Depression counts for suicide in approximately 30 to $70 \%$ of cases, alcoholism for $15 \%$ to $25 \%$. The rate of suicide among drug abusers is at least five times the average(3). Schizophrenic patients have a high suicide rate: over $20 \%$ attempt it, and $10 \%$, eventually succed(4). People who have never married are twice as likely to commit suicide; the divorced and the widowed have the highest rate of all. High unemployment also increases the rates of suicide(5).

The common belief that suicide is a problem only for industrialized countries is unfounded. Reported rates throughout the world are consistently higher among men than women regardless of age group $(6,7)$. Variations of suicide rates in countries are due to cultural differences, motivation and methods of collecting data. Severe stressors, painful terminal illness or overwhelming events can lead to suicide without any apparent or any prior psychopathology(8). A dynamic relationship between a person's social context and the pain he or she feels can be obscured from whatever source

There are no official statistics that reflect the magnitude of suicide or para suicide in Tanzania. Recent reports from the police indicate that suicides are among the most frequently reported cases of fatalities(9). Trigger factors and means employed have so far not been investigated. 


\section{MATERIALS AND METHODS}

Muhimbili National Hospital is the largest of Tanzania's consultant hospitals and the main University teaching hospital with a bed-capacity of 1500 . Most referrals to Muhimbili come from district and private hospitals, clinics, and dispensaries within the city of about three million inhabitants. The departments of Psychiatry, Morbid Anatomy and Pathology belong to 18 departments under the faculty of Medicine. The Department of Psychiatry has 70 beds and four psychiatrists and a psychologist. The department of Histopathology and Morbid Anatomy with seven pathologists carries out at least 1000 autopsies annually. Although the capacity of the mortuary is 25 corpses at a time, twice as many corpses are frequently stored in a single cold room. All medico-legal post-mortems from Dar es Salaam region are carried out at Muhimbili. Since the number of autopsies carried out at Muhimbili is about 1000 annually, and the national suicide rate has so far not been established, a tenth of the annual post mortems was considered a suitable sample size for this study.

Procedure: From 3rd September 2000 to 11th October 2001, one hundred and eleven suicides were identified at the Muhimbili mortuary. They consisted of all reported cases of suicides from Dar es Salaam region, including all identified and recorded successful suicidal attempts. However, eleven cases were not included in the study because the required particulars related to the deceased were lacking. One hundred suicides qualified for the study. Collaborative information from the police and the courts of law was also sought to clarify the motives and means of committing suicide. Medico-legal autopsies were then carried out to establish the causes of death, how the selfinflicted fatal injuries were executed and to identify the used objects/chemicals to complete suicide.

Interviewed key-informants were adult family members, spouses, and workmates, close friends to the deceased and/or any other persons with the reliable needed information who knew / or were present or closest to the deceased at the time of committing the suicidal act. The key-informants were then led to the department of psychiatry for interview by the first author. The interviews were conducted in a quiet room after the objectives of the study had been explained to the key-informants, and informed consent obtained. The interviews embraced empathy and allowed sufficient time for the grieving interviewees to open up in details.

A structured questionnaire employed to interview the key persons focused on the socio-demographic particulars of the deceased, prevailing social conflicts or circumstances associated with the suicidal acts, health problems which could have influenced the deceased to commit suicide, or any other causes (like the amount and frequency of alcohol consumed regularly) which to their best knowledge contributed significantly to the suicidal act. Hospital notes were additionally consulted for any additional information pertaining to suicide. Written messages or oral information left behind by the deceased were also studied to access actual causes for suicide and the means employed to complete the acts. Each case underwent post-mortem to establish the main physical causes of death and/or any other significant but relevant findings. Samples of blood, urine, stomach contents, liver and kidney tissues were taken for laboratory analysis where necessary. Since people infected with human immunodeficiency virus are known to have a higher rate of suicide compared to non infected individuals, a sample of blood was also taken to test for ELISA HIV infection in each case. After the above investigations had been completed, the investigators discussed their findings so as to foster consensus concerning the individual characteristics, the reasons, the causes of death and the means employed for selfannihilation in each case.

Ethical precautions: Consent to carry out the study was sought from the respective medico-legal authorities in Dar es Salaam region. Informed consent was obtained willingly from all key-informants after they had understood the objectives of the study. The names of all the suicides were kept strictly confidential as they were recorded and treated as numbers only. After data cleaning, it was entered into a computer and analyzed using Microsoft Excel program. The frequencies of individual items were recorded, the mean age and the amounts of chemical ingested were then calculated

\section{RESULTS}

Demographic characteristics: As shown in Table 1 below, 53 males and 47 females of mean age 28.2 years $( \pm 10.2)$ (15 to 59 years) were identified. On average, males were aged 33.2 years while females were 23.2 years old. Seventy-two subjects had primary education, 19 secondary, five had higher education and four were illiterate. Sixty-two subjects were single, 30 married, six divorced and two separated. Thirty-nine suicides had been unemployed, 20 were petty businessmen and seven housemaids. The remaining 34 subjects had varied professions. Three subjects were reported to have attempted suicide previously. There was a past history of suicide in families of seven suicides.

Table 1

Socio-demographic characteristics of suicides from Dar es Salaam region

\begin{tabular}{lll}
\hline Gender & Male & $(\mathrm{n}=53)$ \\
& Female & $(\mathrm{n}=47)$ \\
\hline
\end{tabular}

Educational level

Illiterate 4

Primary 4

Secondary 72

College/University

Family status

Single

5

Married

Divorced

Separated

6

2

Occupational status

Unemployed 39

Petty business $\quad 20$

House maids $\quad 7$

Other professions $\quad 34$

Reasons for committing suicide: Definite reasons for committing suicide were established in 61/100 subjects. These consisted of social conflicts in 35 cases (57.3\%) (Table 2). The social problems consisted of acute marital and family conflicts, disappointments of partners in love affairs, and unwanted pregnancies. Painful chronic physical ill health accounted for reasons in 11 cases while major 
mental afflictions involved five suicides. Unexpected financial losses and grinding poverty were reported in ten subjects. Chronic mental illnesses were causes of completing suicide in five subjects who were observed to have been socially withdrawn, their emotions varied easily without reasons, they neglected themselves, often talked nonsense, walked about aimlessly and exhibited aggressive behaviour. Two of them had previously been diagnosed to suffer from psychosis at the Muhimbili psychiatric ward.

Table 2

Reasons for committing suicide in Dar es Salaam region

\begin{tabular}{lll}
\hline Reason & No. of subjects & $(\%)$ \\
\hline Social conflicts & 35 & 57.3 \\
$\begin{array}{l}\text { Painful chronic } \\
\text { physical illness }\end{array}$ & 11 & 18.0 \\
$\begin{array}{l}\text { Economic deprivations } \\
\text { Chronic mental illnesses }\end{array}$ & 10 & 16.4 \\
\hline Total & 5 & 8.2 \\
\hline
\end{tabular}

Methods employed to commit suicide: Sixty nine of the subjects committed suicide by poisoning (Table 3 ). Notably, all the women in the study cohort except one poisoned themselves. Twenty eight subjects employed anti-malarials (mostly chloroquine) to poison themselves. Blood chemical analysis of eighteen cases yielded chloroquine concentration of $34.38 \mathrm{mg} / \mathrm{Kg}$ body weight. Alkaloids for quinine intoxication were detected in four instances. Twelve subjects poisoned themselves with pesticides (steladone, and diazinone) but only in eight subjects were these poisons chemically detected. However, in 29 cases, the used poisons could not be identified. Twenty seven subjects hanged themselves, two shot themselves through the head with guns while one stabbed himself with a knife and a woman jumped down from a high building. Seventy two subjects committed suicide at home. Most suicidal acts were carried out secretly in their bedrooms. Twenty eight subjects committed suicide in their residential neighbourhoods.

\section{Table 3}

Reported methods of committing suicide in Dar es Salaam region

\begin{tabular}{llll}
\hline \multirow{2}{*}{ Method employed } & \multicolumn{3}{c}{ Subjects by Gender } \\
& Males & Females & Total \\
\hline Poisoning & 23 & 46 & 69 \\
Hanging & 27 & - & 27 \\
Gun shots & 2 & - & 2 \\
Stabbing & 1 & - & 1 \\
Jumping from heights & - & 1 & 1 \\
\hline Total & 53 & 47 & 100 \\
\hline
\end{tabular}

Additional risk findings: Of the 33 subjects known to drink alcohol regularly 23 exhibited abnormal behaviour suggestive of alcohol dependence Their moods fluctuated often talked excessively walked unsteadily and had social conflicts after they consumed large amounts of alcohol. Eleven subjects had drunk alcohol excessively within 12 hours prior to committing suicide. Sixteen males of average age 34.6 years and ten women of average age 27.6 years were HIV-sero-positive. Eight of the sero-positive cases presented with clinical features of advanced acquired immunodeficiency syndrome.

\section{DISCUSSION}

Many traditional African cultures consider committing suicide a taboo. They thus frown upon suicide and condemn it morally $(10,11)$. Rapid social changes particularly in urban populations are causing moral instability and the loss of familiar norms which inhibit suicidal behaviour. This study involved 53 males and 47 females whose mean age was 28.2 years. Comparatively, females succumbed to suicide at an age ten years younger than males. The young age at suicides in this study contrasts with that of the elderly in Western Europe who have the highest rate of suicide $(6,12)$. More men than women completed suicide. This finding is consistent with reported suicide rates throughout the world, which underscores higher rates among men than women regardless of age group $(4,7)$.

Three-quarters of the subjects had low primary education. The low educational level is likely to have curtailed their social support and opportunities to financial rewarding employment. Moreover, two thirds of the suicides were either unemployed or under employed as petty business-people, labourers and housemaids. About a half of the Tanzanian population belongs to soft-core poverty, while a third belongs to hard-core poverty(13). Forty percent of adults in Dar-es-Salaam, mostly young adults were recently reported to be either unemployed or underemployed and lived in overcrowded, unhygienic poor houses. This sub-population is exposed to overwhelming stressors from constricted opportunities and limited expectations in life(14). Joblessness is strongly related to suicide. Unemployed men in Italy have been reported to be 3.4 times more likely to commit suicide compared to employed counterparts(15). Sixty two subjects were single at the time of committing suicide while thirty percent were married. Marriage more than parenthood has been observed to offer immunity to suicide(16).

Reasons for committing suicide: The main determinants of suicide typically relate to either psychopathology or to social forces. Reasons for suicidal behaviour are complex and difficult to clearly evaluate. In most cases, risk factors include, antisocial or aggressive behaviour, family turmoil, substance abuse and stress in one's life(17). Clinical research indicates that $90 \%$, or more of suicides have been diagnosed or retrospectively 
meet criteria for a psychiatric disorder(7). Thirty-five subjects committed suicide because of overwhelming social factors. These consisted of marital conflicts and disappointing love relationships associated with infidelity amongst twenty five male partners while conflicts emanating from divorce and unwanted pregnancies involved ten cases. Divorce and marital conflicts were overridden with violence inflicted on female partners who were also sexually abused. These perturbing experiences triggered intolerable emotional outbursts culminating in fatal self-poisoning.

Twenty-six suicides were sero-positive for HIVinfection. This rate is at least twice the national rate among sexually active adults. Amongst eleven subjects who committed suicide due to chronic physical illnesses eight had advanced AIDS with severe multiple inter-current infections including pulmonary tuberculosis, fungal infections and dermatitis at post-mortem. Their unendurable suffering amidst socio-economic deprivations motivated them to end their anguish. The risk of committing suicide in patients with HIV infections has been found to be 35 - 40 times higher than that of HIV-negative persons(18). The risk in this group tends to be higher if the HIV-infection is advanced and is accompanied with disabling inter-current illnesses amidst grinding poverty.

Patients with schizophrenia are known to be at high risk for suicide attempts and dying by suicide(19). In this study, five subjects committed suicide due to chronic mental illnesses. Ten subjects suffered from severe socioeconomic deprivations(Table 2). These included sudden unexpected financial losses through petty business transactions and hardships of life due to unpaid meagre salaries especially amongst housemaids and labourers. Seven suicides had a history of completed suicide in their families. Suicidality and impulsive aggression are thought to be partially heritable.

Employed methods of committing suicide: Cultural values and social policy influence preferences for methods of suicide. Patterns of prescribing medicines do influence trends in substances used in overdose.

Two-fifths of those who poisoned themselves employed antimalarials to kill themselves. Disregard of The Pharmaceutical and Poison Act occurs rampantly because of inadequate supervision over dispensation of treatment drugs. People who decide to poison themselves can easily procure enough doses to kill themselves over the counters without formal prescriptions. Chemical analysis revealed that only $18 \%$ of the suicides had lethal blood levels of chloroquine. This discrepancey is partly due to lack of the needed materials and chemical reagents. Doses of $5 \mathrm{gms}$ chloroquine given parenterally or in concentrations of $3.5 \mathrm{mg} / \mathrm{Kg}$ body weight(20) are usually fatal. Overdoses of chloroquine cause acute deleterious effects on cardiovascular system, which readily, can lead to death. Quinine was detected in four subjects who had ingested tablets to kill themselves. In overdose, quinine depresses and paralyses medulla oblangata. Fatal doses are in excess of $0.6 \mathrm{gm}$ within 24 hours. Eight suicides used pesticides containing organophosphorous compounds, chlorinated hydrocarbons and rodenticides, phosphorous compounds cause acetylcholine to accumulate at synaptic junctions inducing muscle twitches that progresses to flaccid paralysis, cardiac, arrhythmia, also respiratory depression and death(21).

Alcoholism is the second most frequent psychiatric disorder among those who die from suicide. It is usually present in 15 - $25 \%$ of cases and the risk of suicide by poisoning has been found to be twice that in the general population(22). In recent years pressure on sales of alcoholic beverages have facilitated availability of alcohol throughout Tanzania. A third of suicides in this study were known to take alcohol regularly. Twenty three of them were alcohol depedent and 11 cases had drunk alcohol excessively within twelve hours before the suicidal acts.

Men tend to use more violent methods of killing themselves. Hanging was the second most popular method of self- killing. Of the twenty seven deaths by hanging, all were males who used ropes, belts, wires or sheets of cloth. More men than women in this study employed more violent methods of hanging and gunshots. Only in one instance did a woman suffering from AIDS and mental illness kill herself by jumping from a high maternity ward following a septic Caesarean section. In industrialised societies, more people own guns compared to people in developing countries. Those who use guns are overwhelmingly young males $(93 \%)$ who are under the influence of alcohol(23). The site of injury is predominantly the head as also established in this study.

Athough there were limitations to establish clear reasons for committing suicide due to lack of facilities to analyze some of the ingested poisons, some important factors were non the less established. The causative factors of suicide were associated with male sex, intense social conflicts, presence of medical illness, grinding poverty, abuse of alcohol and previous suicidal attempts. Clinical staff should be aware of the importance of alcohol as an accompanying risk factor for suicides. Programmes to strengthen families and to support person at risk of suicide (like HIV-infected) can exert a significant preventive influence. Regulation and limiting of possessions of firearms in communities will minimise suicide. Effective social support in the socially dislocated groups and in the economically disadvantaged, in urban populations is necessary to lower the feelings of hopelessness.

These findings call for further studies to identify subpopulations at high risk for suicide and social trends towards planning of intervention programmes to reduce suicide rates. Surveillance is a critical public health tool for the control of pesticides and poisons(24). Since most suicides occurred at home, it is urgently important that family members be aware of suicide warning signs in suicidal relatives. People suffering from mental afflictions and those with severe physical pain need close surveillance so as to detect suicidal ideation and to intervene early to 
avert suicidal acts. Lastly a tighter policy to control prescriptions of toxic drugs like antimalarials, and pesticides needs to be in place to curb misuse of these drugs for suicides.

\section{ACKNOWLEDGEMENT}

We are grateful for a grant of Tshs. 900,000 by SIDA/ SAREC Research Capacity strengthening MUCHS which partly met the expenses for this study.

\section{REFERENCES}

1. Desjarlais, R. Eisenberg, L. Good, B. and Kleinman, A. World Mental Health: Problems and Priorities in Low-income Countries New York Oxford, Oxford. 1995.

2. Earter, D. and Appleby, L. Case register study of suicide risk in mental disorders. Brit. J. Psychiat. 1999; 175:322-326.

3. James, I.P. Suicide and mortality among heroin addicts in Britain. Brit. J. Addiction. 1987; 62:291.

4. Murphy, E. Lindesay, J. and Grudy, E. 60 years of suicide in England and Wales. Arch. Gen Psychiat. 1986; 43:969 -976

5. Koivumaa-Honkannen, H. Honkannen, R. Viinamaki, H. et al. Life satisfaction and suicide: a 20-year follow-up study. Amer. J. Psychiat. 2001; 158:433-439.

6. Bennet, A. T. and Collins, K., Suicide: a ten -year retropective study. J. Forensic. Sci. 2000; 45:1256-1258.

7. Reza, A Mercy, J. A. and Krug, E. Epidemiology of violent deaths in the world. Inj. Prev. 2001; 7:104-111.

8. Leinerweber, M. Bjerregaard, P. Baereldt, C. and Voetermans, P. Suicide in a society in transition. Int. J. Circum. Hlth. 2001; 60:280-287.

9. Rutazamba, T. D. Road traffic problems as part of urban crisis and health in economic challenge in Tanzania today. Tanzania Public Health Association. (TPHA.) 1991.

10. Swift, C.R. Mental Health Rural Health Series, 6. African Medical and Research Foundation. 1977.

11. Swantz, Marja-Liisa: Ritual and Symbol in Transitional Zaramo
Society Scandinavian Institute of African Studies Upsala. 1986.

12. Carlsten, A; Waern, M. and Allebeck, P. Suicides by drug poisoning among the elderly in Sweden 1969-1996. Soc Psychiat. Epidemiol. 1999; 34:609- 614.

13. Mujinja, P. Poverty and health socioeconomic and political determinants of health Scientific paper presented at TPHA annual Conference. 1997.

14. Ndosi, N.K. The challenges of psychiatry amidst economic deprivations and social change in Dar-es-Salaam Tanzania. In: Broadening the mental health agenda with special reference to Eastern Africa and Research Activities of The East African Health and Behaviour Program Monograph 3 SOSMED Publication. 1998; 22 - 31

15. Preti, A and Miotto, P. Suicide and unemployment in Italy 1982-1994. J. Epidemiol Comm. Health. 1999; 53:694-701.

16. Watt, J.R. The Family, Love, and Suicide in Early Modern Geneva. J.F. Hist. 1996 21:63-86.

17. Miles, C.P., Conditions predisposing to suicide a review; J. Nerv. Ment. Disorders. 1977; 164:231.

18. Rajs, J. and Fugelstad, A. Suicide related to human immunodefiency virus infection in Stockholm. Acta Psychiat. Scand. 1992; 85:234.

19. Radonlsky, E.D., Haas, G.L., J.J and Sweene, J. A. Suicide behaviour in patients with schizophrenia and other psychatry disorders. Amer. J. Psychiat. 1999; 156: 15901595.

20. Narayan, K.S and Reddy, K.S.N. The Essentials of Forensic Medicine and Toxicology 19th (eds) Medical Book Company. 2000; 430-437.

21. Van Rooyan, M; Kirsch, T; Clem, K and Holliman, C.J. Emergent Field Medicine Mc Graw Hill Companies. 2000;644-658.

22. Taylor, C; Cooper, J and Appleby, L.. Is suicide risk taken seriously in heavy drinkers who harm themselves? Acta Psychiat. Scand. 1999; 100:309-311.

23. Mong, S. J., Lyle, J. A. and Black. M. A review of gunshot deaths in Struthclyde. 1989-98. Med. Sci. and Law. 2001; 41:260-265.

24. London, L. and Bailie, R. Challenges for improving surveillance for pesticide poisoning: policy implications for developing countries. Int. J. Epidemiol. 2001; 30:564-570. 